\title{
8. Unemployment and well-being
}

Brendan Burchell and Alex J. Wood

\subsection{Introduction}

Research by psychologists and others has consistently found that employees experience better psychological wellbeing than those who are unemployed. This finding has proven remarkably robust across time and across countries, and seems to affect all groups regardless of their age, sex or social class. Finding a theoretical framework to understand the negative psychological consequences has, on the other hand, generated a lot of controversy despite many decades of serious research on the subject. There is consensus that unemployment cannot be understood in simply economic terms, but requires psychological insight. Some theorists have focused on the good things about being in paid work, others on the distinctly negative things about unemployment. This chapter will describe some of the most influential theories, and how well they are supported by empirical evidence, before considering their applicability in a wider variety of settings. The theories were generated in a time when employment in industrialised countries was more homogeneous; people went to the factory or office, worked and then went home. Now many employees' lives have moved beyond this. The shift away from manufacturing to service industries combined with the internet and mobile technologies such as laptops and phones have softened the boundaries around workplaces so that employees can increasingly work from anywhere. And the rise of zerohour contracts and other flexible forms of work scheduling have detracted from the security and predictability of paid work that is central to many psychological theories of wellbeing. A growing awareness of the very different labour markets that exist in developing countries, where the boundaries between employment, self-employment and work within the family have also challenged the applicability of our understanding of employment and unemployment. This chapter will provide a solid coverage of the conventional material in this area as well as a critical analysis of its global applicability in the 21st century.

\subsection{Unemployment and mental health}

Some people enjoy being unemployed. It can provide them with more leisure time than they had been used to as an employee or a student, and it can be a welcome relief from an unpleasant job. Some people use a spell of unemployment as an opportunity to achieve a 
goal that they previously did not have time to do such as voluntary work, political activism, a sporting achievement, or to spend more time caring for young or elderly relatives.

Unfortunately, such people are rare. Having large numbers of willing and able workers idle is an illogical or absurd situation from many perspectives. Economically, it is a wasted resource; idle workers do not contribute to the output of the nation, do not pay taxes and consume welfare benefits. The results of a large body of research extending over many decades leaves us in no doubt that the more typical reaction to unemployment is not only economic hardship but also a challenge to individuals' wellbeing in the form of symptoms of anxiety and depression, low self-esteem and an inability to enjoy life or to 'flourish'. At any one point in time over the past forty years, unemployment is being experienced by tens of millions of people in Europe alone. It is a source of such misery on such an enormous scale that it deserves to be taken very seriously by psychologists, economists and policy makers.

The literature linking unemployment to poor mental health has been systematically reviewed on a number of occasions. Paul and Moser (2009)'s international review concluded that there was very strong evidence not only that unemployment was correlated with poor psychological health but also that the unemployment caused the poor psychological health. This effect seemed to hold across a wide variety of different types of person and situations, but the effects were always negative. Men, particularly blue-collar men, fared worse than women.

Another international meta-analysis published by McKee-Ryan, Song Wanberg and Kinicki (2005) came to similarly unequivocal conclusions, although they tended to emphasize the psychological attributes that could moderate the effects of unemployment; individuals who held work to be less central to their lives and individuals with better coping strategies seemed to be somewhat protected from the negative effects.

Socially, unemployment is seen as unjust and exacerbates a variety of social problems including inequality, crime (Hagan, 1994), homelessness and divorce (Lampard, 1994), to name but a few. Additionally, many of the individuals who experience unemployment themselves suffer problems of poverty as well as poor physical and psychological health. It is psychological health which is mainly considered here, although it will be argued that one cannot fully understand the psychological effects of unemployment without also 
understanding the social and economic correlates of employment and unemployment. We should also be aware that there is good evidence that the individual deprived of paid work is not the only person to suffer negative consequences; there is also strong evidence that the psychological health of the spouse or partner can suffer, as can the psychological and educational development of children in the household ( Fagin and Little, 1984).

In fact, there cannot be many other areas of psychology where there is so much consensus as the effect of unemployment on wellbeing. But, if we are going to be able to intervene to offset the worst effects of unemployment, we need to be able to understand why unemployment has such negative effects. This has proven to be a far harder task and has generated many different theories and much argument.

Before we move on to examining those theories that attempt to explain this link between unemployment and mental health, we will take a few words to define employment and unemployment.

\subsection{Definitions}

Employment should be fairly easy to define as a relationship between two individuals, an employee who sells his or her labour in exchange for a wage and an employer. It is assumed that this is an enduring state, unlike paying a self-employed person for job that only lasts for a few hours or days, but there are large grey areas here, for instance people on zero hours contracts or franchisees and in the growing digital platform mediated 'gig economy'.

People who are not employed or self-employed can be in a whole variety of other economic statuses such as being retired, a full-time student, a stay-at-home dad, housewife, playboy or unemployed. Unemployment can be differentiated from these other statuses by the fact of wanting and looking for paid work. Again, there are grey areas; some disaffected unemployed people realise that they stand no chance of finding employment, so stop looking for work. Others may only be half-heartedly looking for paid work because they, for whatever reason, prefer not to be employed. But perhaps the most misused word is 'work', particularly when it is used to mean 'employment'. Much work is unpaid, particularly work inside the household to cook, clean and care for others, and even today the majority of that work is done by women (Smith et al, 2013). And 'work' is a very difficult thing to define. 
Sometimes it is unpleasant (what economists call a 'disutility') but actually most people report liking their jobs. Sometimes it is paid, but not always. The best definitions usually suggest that the difference between work and other activities is that we do not just do work for intrinsic pleasure, but to achieve something else, such as a wage, or to care for friends and relations, or to bring about some other desired outcome such as work for a charity. Some think of work as a morally virtuous activity (as in the 'protestant work ethic') but we should perhaps remind ourselves that, by most definitions, conmen and thieves are both performing work!

\section{The social-environmental model of employment}

The most influential approach for understanding the ways in which paid work benefits psychological health is Marie Jahoda’s social-environmental model of employment (also known as her 'latent consequences', 'deprivation' or 'functionalist' theory). This theory has roots in Jahoda's studies of unemployment in Austria in the 1920s, and has been refined and debated by Jahoda right up until her death in 2001 - a remarkable career as a social psychologist spanning seven decades. The central tenet of this approach is the view that employment is a dominant social institution in modern societies (Jahoda, 1992). This social institution provides an important role in contemporary market societies, not only fulfilling our material needs by providing a wage but also furnishing our psychological needs. Those who are excluded from this institution thus tend to suffer severe psychological deprivation. Jahoda argues that while gaining an income is the manifest function of employment, employment also provides five latent functions; or, more precisely, five categories of experience which fulfil psychological needs. These five latent (or 'incidental') functions are: time structure; enforced activity; social contact outside of the family; collective purpose; and status / identity (Jahoda, 1982).

Jahoda's (1982) categories of experience provided by employment

\begin{tabular}{|l|l|}
\hline & Function \\
\hline Manifest & $\bullet$ Income \\
\hline Latent & $\bullet$ Time structure \\
& $\bullet$ Enforced activity \\
& $\bullet$ Social contact \\
& - Collective purpose \\
\hline
\end{tabular}




\section{- $\quad$ Status and Identity}

Jahoda used detailed ethnographic research to illustrate how employment fulfils and reinforces a need for habitual time structures. Jahoda argued that time structures take a rigid form in contemporary societies, and are shaped and impressed upon individuals from a young age by public institutions such as school and the family. Jahoda goes on to argue that public institutions not only create the need for rigid time structures, they also inscribe the need for individuals to fill their days with planned activities. Without the enforced activities provided by employment, people risk boredom and idleness. In fact, as Jahoda stated, employment provides a collective purpose that transcends our individual purposes. Jahoda (1987) details how the major collective purpose instilled in individuals in a capitalist society is that of earning a cash income. So much so, that non-paid work cannot adequately provide status and identity or inclusion within the collective purposes of the larger society in the absence of employment (Jahoda, 1982: 32).

Despite the importance of individualism in contemporary society, people’s 'individualism needs to be embedded in a social context... [and that] outside of the nuclear family, it is employment that provides for most people this social context' (Jahoda, 1982: 24). Without social contact, people are left socially isolated, as employment forces everyone to observe habits, opinions and life experiences different to their own. Jahoda (1982) supports this with the evidence that women who give up employment to look after children often speak of the deprivation of losing social contact outside the family. The final category of status and identity is, in fact, the combination of two categories of experience. For Jahoda (1982), status and identity are conceptually distinct. An individual's identity is a personal notion of an image of themselves and status is anchored in the value system of society. But they are, Jahoda argues, nonetheless closely intertwined because people tend to adopt the status ascribed to a position by society as an element of their identity. In contemporary society, status is largely defined by the job you have. This socially ascribed status then forms one clear way that individuals define themselves and support their self-identity.

In spite of its influence, the social-environmental model of employment has not been without criticism (Cole, 2007; 2008; Ezzy 1993; Fryer, 1986; 2013; Nordenmark and Strandh, 1999; Strandh, 2000). We will therefore assess the strengths and weaknesses of the model 
through elucidating the functions which employment is held to provide while considering each major criticism in turn.

At the most basic level, it has frequently been asserted that Jahoda's framework marginalises the importance of income (Cole, 2007; 2008; Fryer, 1986; Fryer, 2013). However, this line of criticism is somewhat peculiar as Jahoda (1982) identifies income as the first of employment's six functions. Moreover, income is the only function of employment which is manifest, i.e. recognised by the population at large. The importance of income can be seen in the fact that Jahoda (1987) focuses upon it to explain why the unemployed she studied during 1937-1938 in Monmouthshire, Wales, suffered significantly less psychological distress than the unemployed she studied six years previously in Marienthal, Austria. According to Jahoda (1982; 1987) the size and permanence of unemployment benefits constitute the principle explanation. The widely held criticism that Jahoda's framework ignores income, and thus poverty, is perhaps a misreading; her work is most illuminating when discussing the other 'latent' functions which employment provides, and thus it is these sections which draw the reader's attention.

Beyond the lack of attention to income, the social-environmental model has been criticised on other theoretical grounds (empirical support is discussed below). One important criticism which led Jahoda to clarify her approach was the absence of the psychological need to exercise agency (Fryer, 1986). Indeed, Jahoda (1982: 23) argues that most people are unable to:

'single-handedly overthrow the compelling social norms under which we all live and which provide a supportive frame within which individuals shape their individual lives. There are at all times only a few who can manage without it.'

However, Jahoda (1986: 28) would later recognise the 'specification of "agency” as an attribute of being human... 'but the tendency to shape one's life from inside-out operates within possibilities, and constraints of social arrangements... in this sense we are both active and passive.' The idea that we are both active and passive hints towards a notion of duality of structure, which lies at the heart of the structuration (Giddens, 1976; 1979). Furthermore, Jahoda (1986: 110) points out that implicit in the five latent functions is a sixth: personal control - a concept clearly linked to agency and its suppression. 
A further criticism is Jahoda's uncritical acceptance of the benefits of employment, seeing all employment as equally fulfilling necessary psychological needs but paying little attention to the quality of jobs (Fryer, 1986). Cole (2007; 2008) argues that Jahoda sees employment as a telos, an end in itself, due to a hidden normative commitment to the assumed 'supraeconomic' benefits. This simplicity in the theory may have been politically expedient in arguing that mass unemployment was unequivocally a cause of mass human misery, and that providing employment (any employment) was a principle duty of any good government. Yet this minimalism may have had unintended consequences, as that sort of argument was used to deregulate labour markets (for instance, by removing health and safety legislation, or weakening safeguards against long work hours) under the guise of creating more jobs.

This portrayal is not entirely accurate for Jahoda (1981) does state on at least one occasion in her extensive writings that, while most employment provides these positive functions, in some cases it may not provide them to a satisfactory degree. For example, the time structure could be too rigid, the purpose unclear or unacceptable, the status too low or the activity either boring or too exhausting. Jahoda may well have been implicitly referencing a more uniform type of factory or office work which was ubiquitous in most of the twentieth century, but is now less pervasive.

Building upon Jahoda's reflections on both the variability in latent functions and upon control and agency, Warr (1987) developed a more refined social-environmental model termed the 'vitamin model' which elaborated on Jahoda's theory in a number of ways.

\subsection{Warr's vitamin model}

Peter Warr's (1987) vitamin model represents an extension on the core of Jahoda's socialenvironmental model and overcomes many of the problems identified above. Following an extensive review of relevant research, Warr $(1987 ; 1999)$ proposes nine different sets of determinants of whether both employment and unemployment lead to better or worse mental health: opportunity for control; skill use; interpersonal contact; external goal and task demands; variety; environmental clarity; availability of money; physical security; valued social position; and, finally, (in his later writings he added other 'vitamins', such as supportive supervision in (Warr, 1999)). As can be seen, many of Warr's determinates are remarkably similar to Jahoda's categories of experiences. However, of particular importance 
with regards to the criticisms of Jahoda's theory is the inclusion of opportunity for control and environmental clarity as both assume the physiological need for agency. The analogy to vitamins in Warr's model is particularly ingenious. Warr proposes that the determinants which he identifies act in a manner similar to the ways in which two different sets of vitamins affect our physical health. With all vitamins, too little of them is harmful, so if we have been deprived of vitamins it is beneficial to increase our intake of any and all of them. An optimal state will be reached, other things being equal, well before high consumption is reached. Once the optimum plateau has been reached, further increases in vitamin intake will neither improve nor damage our health at least for some time. For some vitamins (e.g. vitamins $\mathrm{C}$ and $\mathrm{E}$ ), this continues to be the case no matter how high the intake, i.e. they continue to have Constant Effects. But with other vitamins (e.g. A and D), too high an intake becomes poisonous, i.e. they result in harmful Addditional Decrements. Warr claims that vitamins 1, 2 and 3 of Figure $x$ have constant effects and vitamins 4 to 9 have additional decrements. The hypothesized differences in the relations between level of intake and level of well-being is depicted in Figure x. Warr also suggested that each individual differed in their own need for each of these vitamins; for instance, introverts would have less need for social contact compared to extroverts.

\section{Figure $x$ around here}

Figure x reproduced from Warr (1987: 234).

\subsection{Essentialism, functionalism and social construction}

Warr's vitamin model represents an important refinement of Jahoda's model, yet it does not overcome all criticism of the social-environmental approach. A more fundamental critique has been levelled at the social-environmental model, highlighting its essentialist character. Jahoda (1982: 59) cites the anthropological work of Sahlins (1974) to argue that the psychological functions that she identified are not time-bound or culture-bound but are enduring needs of human beings. She claims that these needs have been met in societies without employment (such as pre-industrial societies) by "rituals, religious and community practices” (Jahoda, 1982: 59). However, as Cole (2007: 1143) points out, the functions are 'contingent social constructs cut through with gendered and class-based assumptions' and, therefore, Nordenmark and Strandh (1999:2-3) are insightful in the general thrust of their comment that: 
'the possibility that people have different psychological needs, or that needs can change for individuals and for humans in general, is not something which is easily introduced into the perspective. From a sociological viewpoint, we must be able to incorporate the notion of a changing society and a changing individual.'

Warr is likewise criticized by the social anthropologist Ezzy (1993) for focusing on objective environmental contexts while ignoring how these influence subjective understandings (the importance of which can be seen below with regards to job insecurity research). Nordenmark and Strandh (1999) are correct to argue that psychological needs must be considered as social constructs rather than essential human needs. In fact, Jahoda (1982; 1987) herself paradoxically provides an alternative account in which psychological needs are not essential but rather the specific result of conditioning social institutions: school, the family, market exchange and employment itself. Jahoda (1987) documents how unemployed Welsh miners' lived experience of a collective purpose, status and identity were shaped by the imperative in a market society for people to measure themselves against others according to level of income. As highlighted above, it is also argued that the school and the family 'impress on the young the value of punctuality and the need to fill the day with planned activities' (Jahoda, 1982: 22). That institutions in capitalist society generate a psychological need for experiences which can best be fulfilled through employment, follows logically from Jahoda's argument that employment is a dominant institution in contemporary society. If employment were unsupported and not intermeshed with other institutions, it would be unlikely to have persisted for the last 400 years. Jahoda would not claim that employment in its modern form was created deliberately as a psychologically beneficial environment as a philanthropic act by factory owners in the early industrial revolution, but rather she claims that its survival over the centuries is testament to its compatibility with human needs. As Wright (2010: 193) argues, 'social structures and institutions... require vigorous mechanisms of active social reproduction in order to be sustained over time.’

Elaborating the social-environmental model in this way opens it up to another criticism, that of being a functionalist explanation. In fact, Nordenmark and Strandh (1999) and Strandh (2000) confusingly suggest that Jahoda's framework is 'functionalistic.' Cohen (2002) points out that the terms functionalism, functional explanation and function are the source of serious confusion amongst social scientists. Functionalism is a theoretical conception of society within which all the elements reinforce one another. This is quite different to both 'functional 
explanations' and 'explanations of functions'. However, functionalist explanations are usually criticised due to this confusion. Unlike functionalism, there is no reason for functional explanations of social reproduction to be automatic, and can equally be the result of unintentional and dynamic societal conflicts. As Wright (2010: 276) puts it, 'if there are strong tendencies for particular institutions to contribute functionally to social reproduction, this is the result of the history of struggles over social reproduction and the resulting process of institution building, not some automatic, functional logic of the system.' Cohen (2002: 282) demonstrates this point with the example of religion. If we imagine that ten societies required a religion, and each were visited by a prophet, but of the ten only one accepted the prophet's teaching. However, they accepted him not because they needed him but rather because they liked his looks; the other nine societies would then perish, leaving only the society with a religion. This shows that in this example that while 'there is a religion, and it is needed, it does not show that there is a religion because it is needed' (Cohen, 2002: 282). Likewise, in showing that there is employment and that it is needed to fulfil psychological functions, Jahoda does not necessarily show that there is employment because it is needed to fulfil psychological functions.

Another important difference between the approaches of Warr and Jahoda is in the scope of their intended applicability. Jahoda was narrowly focussed on accounting for the difference between employment and unemployment. Warr had greater aspirations, to be able to account for not only the psychological effects of employment and unemployment, but also to be able to understand the positive and negative effects of other environments, such as being a student, a stay-at-home parent or being retired. He was also optimistic that a knowledge of the effects of different economic environments on well-being could lead to our ability to improve those environments, not only to improve the quality of jobs, but also to think what 'good unemployment' might look like.

We have argued that the criticisms of the social-environmental model can be overcome. Doing so requires that it be elaborated in line with Warr's $(1987 ; 1999)$ vitamin model while stressing the socially constructed, contingent and subjective nature of the psychological needs which employment fulfils. We now consider some of the empirical support for Warr's vitamins model. 
In the next section of this chapter the various sources of evidence concerning the psychological health of individuals in the workforce are discussed. The reasons why individuals seem to depend on employment to maintain their psychological well-being will then be considered.

\subsection{Researching Environmental Functions and "Vitamins"}

As outlined above, the social-environmental model of employment postulates that paid work provides a healthier environment for the individual. It also suggests that the unemployed person, without the benefits which commonly accrue from such an environment, will suffer psychological ill-health. Warr's vitamin model (1987) and Jahoda’s “latent functions” or “deprivation” framework (1982), both described earlier in this chapter, both attribute the poor psychological health found among the unemployed to their lack of access to the good things about employment. Although Warr's model was largely derived from his own systematic review of many hundreds of empirical reports on employment and wellbeing, it is difficult to definitively demonstrate the causal link between functions / vitamins and unemployment.

One methodological challenge facing the researcher is to separate the direct causes of unemployment from an alternative account known as the 'selection hypothesis' whereby the association between poor well-being and unemployment is due to people with poor health being more likely to lose their job or remain unemployed for longer (Buffel et al., 2016). For this reason, the best empirical evidence for the effects of unemployment cannot rely on simple cross-sectional studies but typically compares the same individuals when they are employed and unemployed, or tracks changes in public health at an aggregate level and correlates that with rates of employment and unemployment.

The methodological problems of testing theories as to why unemployment effects well-being can be more difficult to overcome. Here the causal ordering is even more difficult to detect. For instance, a correlation between a lack of social contact or enforced activity might be well cause depression, as Jahoda would predict. Alternatively, withdrawing from activities and social contact are known to by symptoms of depression, so that could also account for a correlation between depressive symptoms and unemployment. There are, however, a number of empirical studies which are highly suggestive that the causal link between unemployment, and lower psychological health is mediated by the restricted access to Jahoda's functions and Warr's vitamins. 
Waters and Moore (2002) using a sample of 201 unemployed and 128 employed participants find that the unemployed reported higher perceived latent deprivation, higher depressive affect and lower self-esteem. Creed et al. (2001) also find significant associations amongst their sample of 248 unemployed people between both the latent benefits (time structure, activity, status, collective purpose, and social contact) and well-being, and between the manifest benefits (financial strain) and well-being. Financial strain was the largest contributor to well-being followed by status, time structure and collective purpose. Using a representative survey of the German population, Paul and Batinic (2009) also find ( $\mathrm{N}=998)$ that employed people reported higher levels of time structure, social contact, collective purpose, and activity than the unemployed, and that reduced latent functions correlated with psychological distress.

Buffel et al. (2016) show that amongst their sample of 50-65 year-old European men ( $\mathrm{N}=$ $11,789)$ and women $(\mathrm{N}=15,118)$ unemployment is associated with depression. However, this effect is lessened for men when they are a displaced worker; that is, someone who has lost their job due to business closure. It is argued this can be explained with reference to what they term 'employment based social norms' - norms which are shared by other people and partly sustained by their approval and disapproval. Therefore, the lower levels of depression among displaced workers is seen as a consequence of the fact that they will have lost their job together with a group of colleagues while the cause of their unemployment will appear as obviously structural rather than their own fault. Thus, Buffel et al. (2016: 16) argue that their study 'confirms that as the financial situation of respondents has been taken into account, unemployment captures not only the loss of income, but also several socio-psychological factors, such as a loss of status and self-esteem, social isolation and the lack of time structure... These lead to a deterioration of mental health.'

Qualitative studies that are rich in detail also provide support for the importance of employment to identity. For example, Kirk and Wall's (2010) qualitative studies of teachers and bank employees illustrate how employment leads to self-affirmation of identity. Teachers affirm their identity through the creation of a 'teacherly-self', while bank call centre workers use the non-manual nature of their employment to affirm their identity as moving away from the manual working class. Kirk and Wall argue that, through employment, self-affirmation of identity takes place as a result of people's capacity to perform labour, their desire for 
recognition, and as an act of commitment to others. They identify the intersection of four overlapping influences that give rise to employment identity: cultural representations; employment social relations; social location (family, generation and class); and civil engagement.

Researchers have also empirically investigated Warr's (1987) overall vitamin model, albeit to a lesser extent than Jahoda's framework. This is perhaps to be expected, as Warr's model was based much more directly on a large number of empirical studies, whereas Jahoda's theory emerged more organically from her research and personal experiences. De Jonge and Schaufeli's (1998) study is the most explicit test of Warr's model; 1,437 Dutch nurses and nurse's assistants found that job demands were associated with job-related depression (occupational burnout and emotional exhaustion). While this relationship was linear rather than being the expected curvilinear relationship, job autonomy and workplace social support did exhibit the expected curvilinear relationship.

A standardised scale has been developed by Muller et al. (2005) to aid the systematic investigation of Jahoda's theory. Known as the Latent and Manifest Benefits (LAMB) scale, it enables researchers to use standardized measures for all six of Jahoda’s (1982) original latent and manifest functions of employment. Muller and Waters (2012) report that the LAMB scale has been administered to 5,692 participants across 13 studies. All of Jahoda's functions have been found to relate to well-being in at least two or more of these LAMB studies, with financial strain, social contact / support and time-structure being the most frequently related to well-being. Muller and Waters (2012: 35) summarise these studies as having:

\footnotetext{
'consistently predicted that lack of access to the latent and manifest benefits of employment is associated with decreased psychological well-being. This pattern has held across various samples, such as in low-wage earners, people with spiritual beliefs, people who are unemployed or out of the labour force, and people with negative and positive future perspective.'
}

These cross-sectional studies are supported by longitudinal ones, such as Wanberg et al. (1997) and Selenko et al. (2011). Wanberg et al. (1997) investigate the relationship between time structure, (un)employment and mental health. They find that perceived time structure 
increases as individuals move from unemployment into employment. For those that remain unemployed, reduced time structure two months after job loss leads to lower mental health three months later. Selenko et al. (2011) used a sample of 1,026 German respondents (which reduced to 285 by T4) and measured their employment status, psychological health, and access to manifest and latent functions according to the LAMB scale at four time periods each separated by six months. Across the four waves of their study, they found that someone who reports a decrease in latent benefits at one time-point will probably report a decrease in psychological health six months later. After 12 or 18 months the effect of latent benefits was no longer detectable. However, their cross-sectional results only find that financial benefits, social contact and time structure affected psychological health. The lack of effect for collective purpose, enforced activity and status may in part be explained by issues in translating these more abstract functions from the English LAMB scale into German.

In summary, there is ample empirical support for Jahoda's (1982) assertion that employment fulfils manifest and latent functions, and their restriction is associated with psychological well-being. Moreover, there is some evidence to suggest that the relationship between the functions and mental health is curvilinear, as suggested by Warr's (1987) vitamin model. The more difficult task is establishing causality, given the potential for people with poor health being more likely to lose their job or remain unemployed for longer. However, there are some longitudinal studies which indicate that those moving from unemployment into employment report higher perceived levels of at least some manifest and latent functions (financial benefits, social contact and time structure), and that the unemployed who report lower-levels of these functions at one-point in time will also report lower-levels of psychological wellbeing in the future. That causal evidence only exists for some of the latent functions lowering psychological health probably reflects the abstract nature of collective purpose, enforced activity and status and identity, this in turn make them hard to capture in survey items.

\subsection{Environmental Clarity and the Rise of Job Insecurity}

Warr's 'Environmental Clarity' vitamin relates to job security, or more generally to the predictability of the future of ones' job. Burchell (2002) demonstrates how, in the UK, job insecurity increased substantially between 1970-1980, after which it remained fairly constant in the 1990s and up until 2007. Since 2007 a series of severe economic crises (the credit crunch, the Euro crisis and austerity) have effected many parts of our planet, leading many 
more employees to feel unsure of what the future holds for their jobs. For example, in 2012 $25 \%$ of the UK workforce reported that they felt at some risk of job loss (Gallie et al., 2016). Warr (1987: 149) argues that:

'Predictability is valued because anticipation of the nature and timing of potentially aversive events permits possible coping responses... Uncertainty about whether or not undesirable events are likely to occur inhibits these preparatory responses, and has been widely shown in the laboratory and field investigations to give rise to anxiety and other forms of low affective well-being.'

This uncertainty has become known as job insecurity. De Witte’s (2005: 1) review of the psychological literature on job insecurity determines that:

'What typifies this subjective conceptualisation of job insecurity is that it concerns insecurity about the future: Insecure employees are uncertain about whether they will retain or lose their current job. They are 'groping in the dark' as far as their future within the organisation or company is concerned.'

As suggested by the quote above, research into job insecurity often focuses upon potential loss of employment. However, job insecurity does not only involve fear and worry pertaining to potential job loss. In fact, threat to valued job features were also central to Greenhalgh and Rosenblatt's (1984: 441) now classic conceptualisation of 'job insecurity’ in which they state 'loss of valued job features is an important but often overlooked aspect of job insecurity.' Greenhalgh and Rosenblatt (1984: 441-442) suggest that 'the job features principally associated with job insecurity’ are career progress, income stream, status/self-esteem, autonomy, resources and work community. Subsequent research has tended to overlook the perceived threat to valued job features, perhaps due to Greenhalgh and Rosenblatt (1984: 442) arguing that the threat to job features 'is less severe because organisational membership and all that such membership means to the individual is not lost'. Thus Gallie et al. (2016) refer to the insecurity relating to job features as the 'hidden face of job insecurity'. With threat to job features ignored, Burchell (2002) argues that job insecurity has conventionally been conceptualised only in terms of continued existence of employment. Thus, it has been conceptualised as employment insecurity - the threat to continued employment and the connected threat of becoming unemployed - rather than as job insecurity - the threat to a specific job role, its content and characteristics. Employment insecurity has thus been 
operationalised through survey items such as 'In the next 12 months how likely is it that you will lose your job?'

Burchell (2002) suggests that as the loss or erosion of job features can also trigger feelings of job insecurity, 'in today's labour market, many employees are worried not only because they might lose their jobs per se but because they are threatened with the loss of valued job features' (Burchell, 2002: 70). In support of this theory, Burchell (2002: 70-71) highlights that analysis of the 1997 British Skills Survey of 2,500 employed and self-employed respondents finds that $40 \%$ of workers who experienced secure employment (they felt it was unlikely they would lose their job in the next 12 months) and $11 \%$ of workers who experienced very secure employment (they felt it was very unlikely that they would lose their job in the next 12 months) still did not describe their job as being secure. Therefore, Burchell (2002) states that 'this clearly demonstrates that non-specific feelings of insecurity are more pervasive than feelings of impending job loss, and probably include several other aspects of job insecurity”. Researchers often refer to Standing's 8-point classification of economic insecurity (1999: see table below) to clarify the diverse ways in which individuals can experience insecurity: worrying about total job loss is only one of the ways insecurity is a potential threat to well-being. This will become more apparent below in discussing zero hours contracts.

De Witte et al. (2010) also demonstrate that this traditional focus upon employment insecurity alone is problematic. It is only recently that research has taken the insecurity related to valued job features seriously. De Witte et al. (2010) term this perceived threat to valued job features as 'qualitative job insecurity'. Their study of 7,146 Belgian employees in the banking sector finds threats to job features to be just as harmful to well-being as threats to continued employment. Additionally, Gallie et al. (2016) highlight the prevalence of what they term 'job status insecurity'. Job status insecurity is, they contend, comprised of anxieties surrounding unfair treatment at work or having less say, less opportunities to utilize skill, less pay or less interesting work. Gallie et al. find that 23 per cent of the UK workforce in 2012 were very anxious about at least one of these items. 
Standing's (1999) Eight-Point Typology of Economic Insecurity

- Employment insecurity - when the employer can dismiss or lay off workers, or put them on short time without difficulty or costs.

- Job insecurity - when the employer can shift workers from one job to another at will or where the content of the job can be altered or reduced.

- Work insecurity - where the working environment is unregulated, polluted or dangerous in some way, so that the ability to continue to work is at risk.

- Income insecurity - when earnings are unstable, or when transfer payments are contingency-based, not guaranteed.

- Working-time insecurity - when the employer can impose fragmented, shortened or irregular hours without difficulty or costs.

- Representation insecurity - when the employer can impose change in the labour process and refuse to negotiate with effective trade unions and other institutions protecting workers' collective interests.

- Skill reproduction insecurity - when opportunities to gain and retain skills through access to education and training is impeded.

- Labour market insecurity - represented by labour surplus conditions, so that the probability of securing employment is low, with workers readily available wherever jobs arise.

(Adapted from Burchell (2002: 63))

\subsection{Employment insecurity: evidence for the harm to well-being}

The quantitative conceptualisation of job insecurity (threats to continued employment) has consistently been shown to be highly detrimental to individual mental and physical health. For example, a meta-analysis by Cheng and Chan (2008) of 172 independent samples amounting to 132,927 employees demonstrated that job insecurity is negatively correlated to psychological health $(\mathrm{r}=-0.28)$ and physical health $(\mathrm{r}=-0.23)$. The strength of this effect varies between studies. In some extreme cases the stress of job insecurity might have had an even more negative effect on well-being than unemployment, but the meta-analysis tends to show that insecure jobs are better for psychological wellbeing than unemployment, but not as protective as secure jobs. The negative effects of job insecurity also seem to affect most demographic groups equally, regardless of gender, income or social class. Some studies report a non-linear age effect, such that those at the very start and end of their employment careers are less affected by job insecurity than those in mid-career.

\subsection{Schedule insecurity and zero hours contracts}

The discussion so far is based on a literature that developed when the assumption was that most jobs were fairly standardised with regard to type of contract and hours of work, with occasional 'atypical' exceptions. Many researchers claim that the labour market has changed 
through the repeated recessions that have hit most developed countries since the end of a "golden era” of capitalism that lasted from the late 1940s until the early 1970s. Theorists like Standing (2014) and Beck (2000) have argued that contemporary labour markets are characterised by precarious jobs. where, arguably, the literature based on the works of Jahoda and Warr are less applicable.

A recent notable labour market trend has been the growth of temporal flexibility in the workplace. For many, working time is now seemingly unstable and irregular. The perceived growth of temporal flexibility has been a source of considerable public comment and, in some cases, concern. A case in point is that of the increasing numbers of people in the UK reporting that they are employed on zero hour contracts. Zero hours contracts refer to an employment situation which does not guarantee employees any hours of work. This leaves workers with little choice but to accept whatever hours they are given, even when hours are offered to them at extremely short notice. Although difficult to measure, reliable figures suggest that around $801,000^{1}-1.3$ million $^{2}$ people are employed in the UK on zero hours contracts. The perceived increase in the number of people working in this way has become a major political issue in the UK, with a leader of the opposition Labour Party declaring the country to be 'Zero-Zero Britain - a country of zero hours contracts for the poor and zero tax for the rich.' 3 In response to the public concern regarding zero hours contracts, the UK government held a public consultation on the issue in 2014. However, the growth of temporal flexibility is not limited to non-standard employment such as zero hour contracts; standard permanent, and even full-time, workers also experience flexible working time (Wood, 2016). Nor is the pervasiveness of temporal flexibility limited to the UK. In the United States, Golden (2005) found that 28\% of workers report having schedules with variable start and end times. In Canada one third of part-time workers learned of their work schedule with one week or less notice (McCrate et al., 2012). A similar situation exists across Europe where around 35\% of workers report facing changes in their work schedule (Parent-Thirion et al., 2012). Rubery et al. (2005) suggest that temporal flexibility may represent a new regulation of

\footnotetext{
${ }^{1}$ ONS (2016) Contracts that do not guarantee a minimum number of hours: March 2016. Office for National Statistics: London.

${ }^{2}$ CIPD (2015) Zero Hours and Short Hours Contracts in the UK: Employer and Employee perspectives. Policy Report. CIPD: London.

${ }^{3}$ Watt N (2014) Embattled Miliband vows to challenge Britain’s ‘zero-zero’ economy Embattled Miliband vows to challenge Britain’s ‘zero-zero’ economy. The Guardian 12 November 2014.

https://www.theguardian.com/politics/2014/nov/12/miliband-fightback-labour-victims-zero-zero-britain.
} 
working time which has spread far beyond contingent work. In fact, Wood (2016) posits that, while in the past the 'flexible firm' was based upon the numerical flexibility of contingent workers, today’s firm flexibility may be based upon a generalised temporal flexibility.

So, how does increasing temporal flexibility relate to job insecurity? Burchell’s (2002: 63) highlighting of Standing's (1999) typology is important as it includes 'working time insecurity - when the employer can impose fragmented, shortened or irregular hours without difficulty or costs.' Moreover, De Witte et al. (2010) include 'worry that hours of work will get worse' as one of their 10 features of 'qualitative job insecurity'. Additionally, in the case of hourly-paid workers, temporal flexibility can be related to job insecurity and thus environmental clarity in a second manner. Greenhalgh and Rosenblatt (1984) argue that income stream is one of the job features principally associated with job insecurity. The income stream of hourly-paid workers is linked directly to scheduling, as their pay is determined by the quantity of hours they work. Accordingly, temporally flexible jobs may be associated with two forms of job insecurity identified in the extant literature: working time insecurity and income insecurity. The term schedule insecurity is used to denote the confluence of these two forms of insecurity.

Temporal flexibility itself can take two forms: manager-controlled and worker-controlled. Worker-controlled flexible scheduling tends to be introduced to benefit employees by improving their work-life balance. The same is not true for manager-controlled flexible scheduling, which tends to be introduced to contain costs by tightly matching labour supply to demand (Wood, 2016). Lambert (2008) argues that employers are increasingly unwilling to pay for labour which exceeds demand on an hourly or daily basis. In these circumstances, staffing outlay budgets are tightly linked to customer demand with frontline managers expected to closely enforce staffing budget. Research suggests that, despite government and employer claims to the contrary, flexible scheduling cannot be both manager-controlled and worker-controlled (Wood, 2016). For example, Hyman et al. (2005: 719-720) find that “"flexible” working time patterns were only flexible for the employers and actually undermined workers' own coping arrangements.' Lambert et al. (2012: 304) state that 'the zero-sum game created among workers when employers apply strict limits to total labour hours means that control granted to one employee tends to lessen control enjoyed by coworkers.' 
As insecurity is related to uncertainty, it is manager-controlled flexible scheduling which is likely to act as a source of schedule insecurity. This proposition is supported by the findings of Wood and Burchell (2014) whose qualitative research into the experiences of temporal flexibility among retail workers supports a causal link between frequent unpredictable changes to workers' schedules and job insecurity. Workers were found to experience both working-time and income insecurity as a consequence of frequent irregular and unpredictable alterations to their schedules. A clear theme of the interviews which Wood and Burchell (2014) draw upon is the importance of environmental clarity for mental health, with the lack of environmental clarity afforded by manager-controlled flexible scheduling causing stress, anxiety and depressed well-being. Some informants also suggested that these psychological effects could manifest into psychosomatic complaints. Henley and Lambert (2014) provide quantitative support for the proposition that schedule insecurity damages mental health. Using a sample of 256 retail workers they find unpredictable scheduling, particularly last minute changes to schedules, was associated with lower psychological well-being.

There is currently no national level data on schedule insecurity within the European Union. However, Wood and Burchell's (2015) analysis of the 2005 and 2010 waves of the European Working Conditions Survey (EWCS) provides a unique time series on the number of workers who have their schedules altered regularly by their employer. Analysis of this data finds that manager-controlled flexible scheduling increased significantly - more than 2 percentage points - in 11 out of the 15 Western European countries. The biggest increase was in the UK, where the number of workers experiencing this practice increased by 7 percentage points to 24 per cent. These findings suggest that schedule insecurity might be increasingly widespread across many Western European countries. Furthermore, analysis of the data for tens of thousands of employees surveyed in the 2010 EWCS shows that there is a direct linear relationship between the imposition of unsocial (e.g. evenings, nights and weekends), variable or unpredictable working hours and the low wellbeing of employees.

\subsection{Active Labour Market Policies}

Research on and theorizing about unemployment is rarely done as a purely academic exercise. Hopefully it gives us some evidence as to what can be done to reduce the effects of unemployment. Economists have, at various times over the past seventy years, claimed to have ways of controlling the economy such that mass unemployment is eliminated from boom-and-bust business cycles; unfortunately, such optimism has proven unfounded. So, if 
we have to live with unemployment, what can be done to make it less destructive to human wellbeing?

Jahoda was one of the first psychologists to attempt to research alternative ways of living for otherwise unemployed individuals that would ameliorate the negative effects of unemployment. Having read her research a group of wealthy benefactors sought to re-create the positive features of work through other cooperative community activities for unemployed coal miners in Britain in the 1930s. Despite these schemes being well funded, they (by her own admission) failed. Warr was also optimistic that, with his understanding of the important psychological 'vitamins' for a good life, it should be possible to engineer environments that are jobless but healthy. But, not for the lack of trying, nothing has been found that is as effective in curing the effects of unemployment as a good job (Coutts et al., 2014).

Perhaps the best evidence we have of a policy that is effective against unemployment is a type of intervention called Active Labour Market Policies (ALMPs). Rather than just passively giving out benefits to unemployed individuals to cover the basic cost of living, ALMPs try to intervene in a way to deal with the problem, for instance by teaching individuals skills for more effective job search, to provide training to increase their employability, and to give them coping strategies to deal with the setbacks and challenges of unemployment. There is now a growing body of evidence that many of these schemes not only help unemployed people to get back into employment, but also that these schemes themselves improve the psychological health of the participants even if they don't lead to employment. Coutts et al. (2014) argue that some of these ALMPs seem to be effective because they re-create some of Warr's 'vitamins' or Jahoda's 'categories of experience'; some make individuals more resilient to negative life events; and others may be effective because they provide more optimism for the future.

\subsection{A Global Perspective}

Psychologists have often been accused of doing research in a few locations, all in developed western countries, and much of it in the United States of America, and then disseminating research findings as if they applied to humans everywhere. Research on unemployment is vulnerable to this criticism. There have been relatively few studies of the experience of unemployment in less developed countries - for instance Gonzo and Plattner's study of street-unemployment in Namibia (2003). Gonzo and Plattner try to use the same theoretical 
perspectives (such as Jahoda's model of latent functions) to understand unemployment in Namibia, where the lack of any recognisable welfare system forces jobless people onto streets in search for casual employment. This creates a completely different everyday environment to the social isolation experienced by many people in richer countries.

Unemployment pre-supposes that individuals are given some payments (usually from the state or possibly from their family) to search for employment but otherwise to be idle. In many parts of the world, such as most of sub-Saharan Africa, this is far from the norm (Burchell et al, 2016). Analysis of the economic status and work histories of people up to the age of 30 showed that some of the more highly educated individuals do have more westernstyle careers of employment, sometimes punctuated by spells of unemployment. But for many sections of society in developing countries, their trajectories do not include spells identifiable as unemployment. Rather, they alternate between periods of self-employment (often linked to a family business), informal employment, and periods where they are 'family workers' helping with domestic, agricultural or some other family business and being provided with meals and accommodation by the family.

This suggests that we actually know little about unemployment as it is experienced in developing countries. Its nearest equivalent, family work, could be a very different in its psychological consequences of western-style unemployment; time structure and enforced activity might be better, but the economic dependence and lack of control could be far worse.

Other indications about the relative demerits unemployment in richer and poorer countries is mixed. Paul and Moser's (2009) meta-analysis of the psychological effects of unemployment suggested that the wider economic climate can be an important moderating variable; less developed countries, countries that have more unequal income distributions, and countries that spend less on benefits could make the experience of unemployment harsher. Patel and Kleinman (2003) argue that the link between poverty and mental disorders in developing countries is actually caused more by the low levels of education rather than income levels per se. On the other hand, Powdthavee (2007) compared the experience of unemployment in different parts of South Africa and found that where the rate of unemployment was higher, the individual impact was slightly less than in situations where unemployment was relatively rare. Unfortunately there is a stark contrast between the plethora of evidence on the 
relationship between economic status and psychological wellbeing in rich countries and paucity of research in the rest of the world.

\subsection{Unemployment, Job Insecurity, Political Attitudes and Islamic radicalisation.}

Whilst the main thrust of this chapter has been on the individual misery that can be caused by unemployment and job insecurity, it is by no means the only way that individuals and societies can be threatened by economic insecurity. In the UK in the 1980s, when unemployment peaked at close to four million (its highest level since before the Second World War) there was much political concern that this extremely high level of unemployment would make the country ungovernable and lead to a left-wing revolution. This did not happen - in fact it was a period of electoral success for a right-wing conservative party. So, perhaps the opposite is true, unemployment and job insecurity are more likely to favour extreme right wing parties, as argued by Flecker (2016). As this report points out, the mass unemployment in Germany in the 1930s was seen as a major factor leading to the election and then political domination of Hitler.

More careful empirical tests of this hypothesis find little support for a direct link between unemployment or job insecurity and popular support for extreme right wing parties. There do seem to be a few extreme political parties that have gained some popular support in blaming immigrants for "stealing jobs" leading to unemployment, but this only seems to happen in sporadically (Oesch, 2008). In fact, careful empirical analysis of aggregate levels of unemployment, job insecurity and elections suggests that there is more support for the opposite effect - Arzheimer and Carter (2006) analysed actual elections that took place between 1984 and 2001 in the European countries with more established extreme right parties. Somewhat surprisingly, they found that support for extreme right wing parties was negatively correlated with levels of unemployment in Europe. This finding has been replicated by other authors; it seems that voting for extremist parties is more strongly linked to threatened cultural identities than individuals’ economic or employment status.

More recently, research on the political implications of unemployment has shifted to another perceived threat - radicalisation and acts of political violence or "terrorism" connected to Islamic fundamentalist groups. Although the number of sympathisers of political violence for Islamic causes in western countries is very small even amongst Islamic ethnic groups, 
(and the number of fatalities is also relatively small compared to the public health impact of economic crises) the political impact of fundamentalist Islamic terrorism has been significant. A number of studies have looked at the radicalisation process (see, for instance, GithensMazer's 2008 study of North Africans living in the UK), and they tend to conclude that political mobilisation through historic accounts of injustice are more important than poverty and economic deprivation. This has been supported by a large survey of young people of Muslim heritage living in London and Bradford; Bhui, et al. (2014) found that being young, healthy and being in Education rather than Employment were three predictor of sympathising with Islamic political violence. Of those in employment, those with the highest incomes (over $£ 75,000$ per year) were more likely to be sympathisers of violent protest and terrorism. Beyond this, neither unemployment, nor the psychological outcomes of unemployment such as isolation or symptoms of depression and anxiety disorders predisposed individuals towards Islamic extremism. Nevertheless, one of the defining characteristics of modern democratic states is that employment is the normal and stabilizing link between individuals and the capitalist system, so without mass employment, civilization as we know it would change fundamentally.

\subsection{The end of work?}

Just as the employment relationship between an employer and an employee is a relative novelty in the context of human existence, there is increasing concern that we will see its demise in the next few decades.

There have been a large number of predictions that this system should already have collapsed, but these predictions have, so far, proven to be premature. Some of these predictions are based on what are claimed to be fundamental flaws or contradictions in the socio-economic systems based on capitalism. Although capitalism has experienced a number of crises, it has also shown itself, up until now, to be resilient and able to recover from crises.

The other claims for the 'end of work' are based on advances in the technologies that can substitute for humans, thus reducing the need for people to be employed in a whole range of agricultural, extraction, manufacturing, and service industries. Indeed, this "end of work" argument has been made repeatedly with the introduction of new spinning and weaving machines, tractors on farms, computers to replace clerks, and so on. To give one example, 
the number of farmers and farm labourers accounted for 33\% of all employment in the US in 1910, but by the year 2000 it had declined to only 1.2\% (Wyatt and Hecker, 2006). Far from leading to mass unemployment, the proportion of adult populations in employment in western countries has actually increased in most countries (albeit they are working shorter hours than a century ago); at the same time as some occupations like farm labouring were in decline, other occupations have been expanding just as rapidly. For instance, the highly skilled occupations, such as "Professional, Technical and Kindred" occupations have increased from about five percent of employees in 1910 to about 24\% of the US workforce by the end of the twentieth century.

One might draw the conclusion from this that all such 'end of work' predictions will be proven wrong, because as we do away with some jobs, we create other jobs, often to supply luxury goods to ever wider sections of society. However, in the past year, a number of authorities in the field of technology and employment have become increasingly concerned that this 'doomsday scenario' whereby jobs disappear at an alarming rate, rendering even the majority of the working age population unemployed might be about to happen. The reason for this concern is that many experts are confidently predicting that we are on the edge of a revolution in machine learning and big data. Over the next ten or twenty years, many cognitive skills that had been considered as only doable by humans, such as driving, teaching, accounting and so on, will now be performed more economically and to a higher standard by intelligent machines. It is predicted that, when we hit the point of exponential increases in machine intelligence, and those machines are developing their own intelligence, the speed of change will be far more dramatic than anything we have seen before, and the effects on employment could be catastrophic. The latest controversial predictions by Frey and Osborne (2016) are that $57 \%$ of jobs in the richest countries (the Organisation of Economic Cooperation and Development (OECD)) will be taken over by artificial intelligence. If we can no longer provide employment to sustain the wellbeing of the population, societies will need to find an alternative type of economic system if we are to avoid calamitous levels of individual misery and political instability.

\subsection{Conclusions}

Unemployment, as experienced in western societies, is a colossal source of misery. We now have a large body of evidence that helps us to understand what it is about employment that protects individuals' wellbeing. Where there is the political will to help rather then to blame 
the jobless, we can use this knowledge to ameliorate the suffering associated with unemployment. We should be mindful that not all jobs are good jobs: for instance insecure and zero-hour contracts do not provide as many of the benefits as better quality jobs.

In richer industrialised and post-industrial countries we have become used to societies where full-time employment is the normal activity for adults between leaving education and retiring. There is now good reason to worry that this era might be coming to an end and we will need to find some alternative socio-economic systems for a future where the amount of paid work halves. Maintaining stability and wellbeing in such a scenario will provide the biggest challenge yet for economic psychologists.

\subsection{References}

Arzheimer K and Carter E (2006) Political opportunity structures and right-wing extremist party success. European Journal of Political Research 45(3): 419-443.

Beck U (2000) The Brave New World of Work. Cambridge: Polity

Bhui K, Warfa N and Jones E (2014) Is Violent Radicalisation Associated with Poverty, Migration, Poor Self-Reported Health and Common Mental Disorders? PLoS ONE 9(3): e90718. doi:10.1371/journal.pone.0090718

Buffel V, Missinne S and Bracke P (2016) The social norm of unemployment in relation to mental health and medical care use: the role of regional unemployment levels and of displaced workers. Work, Employment and Society Published online before print March 14, 2016.

Burchell B.J (2002) The prevalence and redistribution of job security and work intensification. In (Eds) Burchell B.J, Ladipo D and Wilkinson F, Job Insecurity and Work Intensification. London: Routledge.

Burchell B.J, Coutts A, Hall E and Pye N (2016) Self-employment programmes for young people: A review of the context, policies and evidence. EMPLOYMENT Working Paper No. 198. Geneva: International Labour Organisation.

Cheng G and Chan D, (2008). Who suffers more from job insecurity? A meta-analytic review. Applied Psychology 57(2):72-303.

CIPD (2015) Zero Hours and Short Hours Contracts in the UK: Employer and Employee perspectives. Policy Report. CIPD: London

Cole M (2007) Re-Thinking Unemployment: A Challenge to the Legacy of Jahoda et al. Sociology 41(6): 1133-1149. 
Cohen G.A (2002) Karl Marx’s Theory of History: a Defence $2^{\text {nd }}$ Edition. New Jersey: Princeton University Press:

Cole M (2008) Sociology contra government? The contest for the meaning of unemployment in UK policy debates. Work, Employment and Society 22(1): 27-43.

Creed P.A and Macintyre S.R (2001) The relative effects of deprivation of the latent and manifest benefits of employment on the well-being of unemployed people. Journal of Occupational Health Psychology 6:(4):324-331

Coutts A.P, Stuckler D, and Cann D.J (2014) The Health and Wellbeing Effects of Active Labor Market Programs. Wellbeing 6:2(13):1-18.

Ezzy D (1993) Unemployment and mental health: A critical review. Social Science \& Medicine 37(1): 41-52.

De Jonge, J and Schaufeli W (1998). Job Characteristics and Employee Well-Being: A Test of Warr's Vitamin Model in Health Care Workers Using Structural Equation Modelling. Journal of Organizational Behavior 19(4): 387-407.

Fagin L and Little M (1984) The Forsaken Families. Harmondsworth: Penguin. Flecker J (2016) (Ed) Changing Working Life and the Appeal of the Extreme Right. Abingdon: Routledge.

Frey C.B and Osborne M (2016) Technology at Work v2.0: The Future Is Not What It Used to Be. Citi GPS: Global Perspectives \& Solutions.

Fryer D (1986) Employment deprivation and personal agency during unemployment: A critical discussion of Jahoda's Explanation of the psychological effects of unemployment. Social Behaviour 1:3-24.

Fryer D (2013) Labour market disadvantage, deprivation and mental health. In (Eds) Wolff C, Drenth P.J.D and Henk T Handbook of work and organizational psychology Vol 2. Hove: Pychology Press Ltd.

Gallie D, Felstead A, Green F and Inanc H (2016) The hidden face of job insecurity. Work, Employment and Society, Published online first January 29, 2016.

Giddens A (1976) New rules of sociological method: A positive critique of interpretative sociologies. London: Hutchinson

Giddens A (1979). Central problems in social theory: Action, structure, and contradiction in social analysis. Los Angeles, CA: University of California Press.

Githens-Mazer J (2008) Islamic Radicalisation among North Africans in Britain. BJPIR 10(4):550-570. 
Golden L (2005) The Flexibility Gap: Employee Access to Flexibility in Work Schedules. In (Ed) Zeytinoglu I.U Flexibility in Workplaces: Effects on Workers, Work Environment and the Unions. Geneva: International Industrial Relations Association and International Labour Organisation, 38-56.

Gonzo W and Plattner I.E (2003). Unemployment in an African country: a psychological perspective (No. 5). Windhoek: University of Namibia.

Greenhalgh L and Rosenblatt Z (1984) Job Insecurity: Toward Conceptual Clarity. Academy of Management Review 9(3): 438-448.

Hagan J (1994) Crime and Disrepute. Thousand Oaks CA: Pine Forge Press.

Henley J.R and Lambert S.J (2014) Unpredictable Work Timing in Retail Jobs Implications for Employee Work-Life Conflict. ILR Review 67(3): 986-1016.

Hyman J, Scholarios D and Baldry C (2005) Getting on or getting by? Employee flexibility and coping strategies for home and work. Work, Employment and Society 19(4): 705725.

Jahoda M (1981) Work, employment, and unemployment: Values, theories, and approaches in social research. American Psychologist 36(2):184-191

Jahoda M (1982) Employment and Unemployment: A Social-Psychological Analysis. Cambridge: Cambridge University Press.

Jahoda M (1987) Unemployed men at work. In Fryer D and Ullah P (Eds)

Unemployed People: Social and Psychological Perspectives. Milton Keynes, Open University Press.

Jahoda M (1992) Reflections on Marienthal and after. Journal of Occupational and Organizational Psychology 65(4): 355-358.

Kirk J and Wall C (2010) Work and identity: historical and cultural contexts. Basingstoke: Palgrave Macmillan.

Lambert S.J (2008) Passing the buck: Labor flexibility practices that transfer risk onto hourly workers. Human Relations 61(9): 1203-1227.

Lambert S.J, Haley-Lock A and Henly JR (2012) Schedule flexibility in hourly jobs: Unanticipated consequences and promising directions. Community, Work and Family 15(3): 293-315.

Lampard R (1994) An examination of the relationship between martial dissolution and unemployment. In (Eds) Gallie D, Marsh C and Volger C Social Change and the Experience of Unemployment. Oxford: Oxford University Press. 
McCrate E, Lambert S and Henly J.R (2012) Schedule instability and unpredictability as sources of underemployment among hourly workers in Canada. Paper presented at the Work and Family Researchers Network Conference, New York.

McKee-Ryan F.L, Song Z, Wanberg C.R and Kinicki A.J. Psychological and physical wellbeing during unemployment: a meta-analytic study. Journal of Applied Psychology 90(1): 53-76.

Muller J.J, Creed P.A, Waters L.E and Machin M.A (2005) The Development and Preliminary Testing of a Scale to Measure the Latent and Manifest Benefits of Employment. European Journal of Psychological Assessment 21(3): 191-198.

Muller J.J and Waters L.E (2012) A Review of the Latent and Manifest Benefits (LAMB) Scale. Australian Journal of Career Development 21(1): 31-37.

Nordenmark M and Strandh M (1999) Towards a Sociological Understanding of Mental Well-Being among the Unemployed: The Role of Economic and Psychosocial Factors. Sociology 33(3): 577-597

Oesch D (2008) Explaining Workers' Support for Right-Wing Populist Parties in Western Europe: Evidence from Austria, Belgium, France, Norway, and Switzerland. International Political Science Review 29(3): 349-373.

ONS (2016) Contracts that do not guarantee a minimum number of hours: March 2016. London: Office for National Statistics.

Parent-Thirion A, Vermeylen G, van Houten G, Lyly-Yrjänäinen M, Biletta I and Cabrita J (2012) Fifth European Working Conditions Survey - Overview report. Brussels: Eurofound.

Patel V and Kleinman A (2003) Poverty and common mental disorders in developing countries. Bulletin of the World Health Organization 81(8): 609-615.

Paul K.I and Batinic B (2009) The need for work: Jahoda's latent functions of employment in a representative sample of the German population. Journal of Organizational Behavior 31(1): 45-64.

Paul K.I and Moser K (2009) Unemployment impairs mental health: Meta-analyses. Journal of Vocational Behavior 74(3): 264-282.

Powdthavee N (2007) Are there geographical variations in the psychological cost of unemployment in South Africa? Social Indicators Research 80(3): 629-652.

Rubery J, Ward K, Grimshaw D and Beynon H (2005) Working time, industrial relations and the employment relationship. Time and Society 14(1): 89-110.

Sahlins M (1974) Stone Age Economics. Hawthorne NY: Walter de Gruyter. 
Selenko E, Batnic B and Paul K (2011) Does latent deprivation lead to psychological distress? Investigating Jahoda's model in a four-wave study. Journal of Occupational and Organizational Psychology 84(4): 723-740.

Smith M, Piasna A, Burchell B, Rubery J, Rafferty A, Rose J and Carter L (2013) Women, men and working conditions in Europe. Publications Office of the European Union, Luxembourg.

Standing G (1999) Global Labour Flexibility: Seeking Distributive Justice. Basingstoke: Palgrave Macmillan

Standing G (2014) The Precariat: the New Dangerous Class. London: Bloomsbury. Strandh M (2000) Different Exit Routes from Unemployment and their Impact on Mental Well-Being: The Role of the Economic Situation and the Predictability of the Life Course. Work, Employment and Society 14(3): 459-479.

Wanberg C, Griffiths R and Gavin M (1997) Time structure and unemployment: A longitudinal investigation. Journal of Occupational and Organisational Psychology. 70(1): 75-95.

Warr P (1987) Work Unemployment and Mental Health. Oxford: Oxford University Press.

Warr P (1999) Well-being and the workplace. In (Eds) Kahneman D, Diener E, Schwarz N Well-being: The foundations of hedonic psychology. New York NY: Russell Sage Foundation.

Waters L and Moore K (2002). Reducing latent deprivation during unemployment: The role of meaningful leisure activity. Journal of Occupational and Organizational Psychology 75(1):15-32.

Watt N (2014) Embattled Miliband vows to challenge Britain’s ‘zero-zero’ economy Embattled Miliband vows to challenge Britain’s ‘zero-zero’ economy. The Guardian 12 November 2014. https://www.theguardian.com/politics/2014/nov/12/milibandfightback-labour-victims-zero-zero-britain.

De Witte H (2005) Job Insecurity: Review of the International Literature on Definitions, Prevalence, Antecedents and Consequences. Journal of Industrial Psychology 4: 1-6

De Witte H, De Cuyper N, Handaja Y, Sverke M, Näswall K and Hellgren J (2010) Associations Between Quantitative and Qualitative Job Insecurity and Well-Being. International Studies in Management Organisations 40(1): 40-56.

Wood A.J (2016) Flexible Scheduling: degradation of job quality and barriers to collective voice. Human Relations 69(10): 1989-2010. 
Wood A.J and Burchell B.J (2015) Zero Hours Employment: A New Temporality of Capitalism? Reviews \& Critical Commentary (CritCom), 16th September.

Wood A.J and Burchell B.J (2014) Zero Hour Contracts as a Source of Job Insecurity.

Report submitted to the UK Government Department of Business Innovation and Skills Consultation on Zero Hour Contracts. Cambridge: University of Cambridge Individual in the Labour Market Research Group Reports.

Wright E.O (2010) Envisioning Real Utopias. London: Verso.

Wyatt I.D and Hecker D.E (2006) Occupational changes during the 20th century. Monthly Labor Review March 2006. 